\title{
The patterns of problematic social media use (SMU) and their relationship with online flow, life satisfaction, depression, anxiety and stress symptoms in Lithuania and in Germany
}

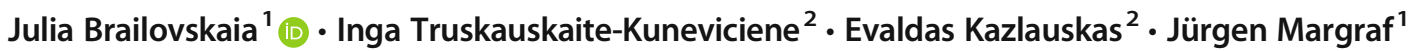

Accepted: 3 April 2021 / Published online: 15 April 2021

(C) The Author(s) 2021

\begin{abstract}
The present study investigated problematic social media use (SMU) in Lithuania and in Germany. In two student samples (Lithuania: $N=1640$; Germany: $N=727$ ), problematic SMU, flow experienced during SMU, life satisfaction, depression, anxiety and stress symptoms were assessed by online surveys. Latent Class Analysis resulted in a four-group classification of participants due to their levels of problematic SMU characteristics: low-symptom, low-withdrawal, high-withdrawal, and highsymptom. The proportion of participants in the low-symptom group was significantly higher in Germany than in Lithuania. In contrast, significantly more Lithuanian participants belonged to both withdrawal groups. No significant country differences were found for the composition of the high-symptom group. In both countries, a series of Structural Equation Models showed that the level of flow, depression, anxiety and stress symptoms was the highest in the high-symptom group, and the lowest in the lowsymptom group. Life satisfaction revealed the reversed result pattern. The current findings show that students from Lithuania and Germany can be grouped considering their problematic SMU level. Individuals in the four groups differ due to their level of mental health. Especially members of the high-symptom group might benefit from external controlling strategies of their time spent on SM, while members of the withdrawal groups are suggested to train their SMU self-control.
\end{abstract}

Keywords Problematic social media use · Flow experience $\cdot$ Depression, anxiety, and stress symptoms $\cdot$ Life satisfaction · Lithuania · Germany

\section{Introduction}

University students often experience high levels of daily stress. Additionally to academic stress due to grade competition and high pressure to perform, they typically have to manage their household and finances for the first time in their life (Wunsch et al. 2017; Habihirwe et al. 2018). To at least temporarily escape from stressors across different aspects of daily life, many young adults engage in multiple interactions on online social media (SM) (Pew Research Center 2019). On platforms such as Facebook, Twitter and Instagram they share

Julia Brailovskaia

Julia.Brailovskaia@rub.de

1 Mental Health Research and Treatment Center, Department of Clinical Psychology and Psychotherapy, Ruhr-Universität Bochum, Massenbergstr. 9-13, 44787 Bochum, Germany

2 Center for Psychotraumatology, Institute of Psychology, Vilnius University, Ciurlionio 29-203, 03100 Vilnius, Lithuania their experiences with a broad audience and receive positive feedback in form of "Likes" and positive comments (Marengo et al. 2021). Particularly individuals with enhanced levels of depression and anxiety symptoms - who often feel overwhelmed by their daily obligations - tend to immerse into the SM world (Primack et al. 2017).

On SM, they can at least temporarily forget their negative experiences in the offline world, find relief and perceive social support that they often miss offline (Burrow and Rainone 2017). Moreover, previous research showed that intensive involvement in social media use (SMU) can contribute to the experience of flow (Kwak et al. 2014; Mauri et al. 2011). Flow describes a state of intensive intrinsic reward that is positively associated with a high level of pleasure and enjoyment. Activities that evoke the experience of flow are often repeated, even at great cost (Csikszentmihalyi 1990). Flow that is experienced during the use of SM is defined by five typical characteristics: focused attention (intensive focus on the SM activities), enjoyment (experience of pleasure during SMU), curiosity (experience of interest during SMU), telepresence (deep immersion into the SM world), and time-distortion (losing of 
the sense of time during SMU) (Kwak et al., 2014). Online flow seems to belong to the main reasons for intensive SMU particularly in young students who experience high levels of everyday stress (Brailovskaia et al. 2020a).

Despite the positive emotions that can be experienced during SMU, there is currently a controversial debate on potential negative consequences of SMU for mental health. Specifically, previous studies emphasized that online flow could contribute to the develop of an emotional bond to the SM that is linked to the problematic need to stay permanently online (Brailovskaia et al. 2018; Brailovskaia and Teichert 2020; Zhao and Zhou 2021). Problematic SMU is defined by six typical characteristics (Andreassen et al. 2017): salience (permanent thinking about SMU), tolerance (heightened amounts of SMU are required to attain positive effect), mood modification (mood improvement by SMU), relapse (reverting to higher amounts of SMU after unsuccessful attempts of its reduction), withdrawal symptoms (becoming nervous without SMU), and conflict (interpersonal problems caused by intensive SMU).

Earlier cross-sectional investigations found a positive association between problematic SMU and symptoms of depression, anxiety and stress (Koc and Gulyagci 2013; Atroszko et al. 2018; Ryan et al. 2014; Duradoni et al. 2020; Boursier et al. 2020a; Boursier et al. 2020b; Andreassen et al. 2016). Its relationship with life satisfaction was negative (Błachnio et al. 2016). Furthermore, it has been hypothesized that children emotional maltreatment, body image dissatisfaction and an insecure attachment style could serve as antecedents of problematic SMU (D'Arienzo et al. 2019; Kircaburun et al. 2020). In longitudinal studies, problematic SMU was positively linked to the level of insomnia up to six weeks later and suicide-related outcomes (i.e., ideation and behavior) up to one year later (Brailovskaia et al. 2019; Brailovskaia et al. 2020c). In experimental studies, conscious reduction of time spent on SM or a complete waiving of SMU contributed to the increase of life satisfaction and the decrease of depression and anxiety symptoms (Hunt et al. 2018; Brailovskaia et al. 2020b; Tromholt 2016), as well as of problematic SMU (Brailovskaia et al. 2020b). Based on these findings, it has been assumed that intensive use of SM in general and specifically problematic SMU might negatively impact mental health (Griffiths 2019; Longobardi et al. 2020; Boursier et al. 2020b; Brailovskaia et al. 2019).

In contrast, other researchers emphasized that it is important not to over pathologize intensive SMU and not to overestimate its potential impact on mental health (Carbonell and Panova 2017). Problematic SMU has currently not been recognized as a formal psychiatric disorder in the Diagnostic and Statistical Manual of Mental Disorders (DSM-5; American Psychiatric Association 2013) and in the International Classification of Diseases (ICD-11; World Health Organization 2018). It has been argued that there is a lack of an established definition of this phenomenon, of a standardized instrument for its assessment as well as of longitudinal studies on functional impairment and neuronal correlates of problematic SMU (Billieux et al. 2015; Carbonell and Panova 2017; Marino et al. 2018b). Against this background, no or only hypothetical causal conclusions about its antecedents and consequences should be drawn. Furthermore, the reported evidence for the relationship between (problematic) SMU and mental health is often weak (Carbonell and Panova 2017; Orben and Przybylski 2019). Some studies did not find significant associations between the use of SM (for example, time spent on SM or emotional value of SMU) and mental health (Berryman et al. 2018; Coyne et al. 2020). Moreover, cross-national studies that investigate the same hypotheses/ research questions on problematic SMU with the same instruments at once in different countries are rare. This impedes conclusions about the universality of this phenomenon and its relationships (see e.g., Marino et al. 2018a, 2018b).

Thus, the phenomenon "problematic SMU" and its associations currently remain a contentious issue. To contribute to the clarification of this issue, thorough cross-national research is required to understand whether problematic SMU in general, its typical characteristics and its associations with mental health should be considered as a significant universal problem, whether they are rather a local issue of specific countries or whether there is "no need to panic" and to pathologize the online behavior.

A systematic literature search in PubMed and PsycINFO databases and on Google Scholar showed that many available studies on problematic SMU and its potential negative consequences come from the U.S. (e.g., Longstreet and Brooks 2017) and European countries such as Germany (e.g., Brailovskaia et al. 2019), Norway (e.g., Andreassen et al. 2013), Poland (e.g., Atroszko et al. 2018), and Italy (e.g., Casale and Fioravanti 2018). However, only little is known about problematic use of SM in the Baltic region, specifically Lithuania.

Intensive use of SM is highly popular particularly among young people in Lithuania

(The Lithuania Tribune 2016; StatCounter GlobalStats 2021b). But how is the online activity linked to users' mental health? The systematic search revealed only one recently published study from Lithuania that described problematic SMU to be negatively associated with life satisfaction in a sample of school students (Buda et al. 2020). University students belong to the main users of SM in Lithuania (Pribeanu et al. 2015). However, the link between students' problematic SMU and mental health variables remains unclear. Considering the current controversial debate about problematic SMU that among other critical points - refers to a lack of crossnational findings that provide universal evidence, it seems to be of great importance to clarify this issue. Is problematic SMU a relevant issue in Lithuanian students? Can the results 
from other countries (e.g., Andreassen et al. 2017; Atroszko et al. 2018; Brailovskaia et al. 2020a) that refer to a negative relationship between problematic SMU and mental health be replicated in Lithuania? A confirmation of both questions could provide further evidence for the perspective that warns of problematic SMU and its potential negative consequences. In contrast, the lack of its confirmation could plead for the perspective that emphasizes the need not to overestimate the impact of intensive SMU.

Following research on problematic online gaming behavior (Wu et al. 2013), available studies reported that flow experienced during the use of SM could serve as an antecedent of problematic SMU (Brailovskaia et al. 2018; Zhao and Zhou 2021). Therefore, the investigation of the link between problematic SMU and online flow (as a whole construct and its five subscales) in Lithuania cloud provide significant evidence for the current controversial debate on problematic SMU.

In accordance with the dual-factor model (Keyes 2005), mental health consists of two interrelated but separate unipolar dimensions: negative and positive. The inclusion of both dimensions in an investigation is recommended to allow a full consideration of the mental health level. Notably, available research from different countries reported that young adults with enhanced levels of depression, anxiety and stress symptoms often tend to intensive use of SM to at least temporarily escape their overwhelming obligations. While in the shortterm this typically contributes to the experience of positive emotions, they could be at enhanced risk for problematic SMU in the longer-term (Atroszko et al. 2018; Boursier et al. 2020a); and problematic SMU could in turn contribute to conflicts in the offline world and thus further enhance the negative symptoms (Brailovskaia et al. 2019; Brailovskaia and Margraf 2017; Boursier et al. 2020b). Furthermore, it was assumed that especially individuals with low levels of life satisfaction tend to escape into the online world to gain social support and to experiences positive emotions. Therefore, they could be at increased risk for the development of an emotional bond to the SM and the tendency for problematic SMU (Błachnio and Przepiórka 2018). Against this background, it seems reasonable to consider depression, anxiety and stress symptoms as indicators of the negative mental health dimension, and life satisfaction as an indicator of the positive mental health dimension when investigating the relationships of problematic SMU in Lithuania.

Thus, to close the described research gap and to contribute findings from the, so far, less investigated Baltic region to the clarification of the current controversial debate, the present study aimed to investigate problematic SMU and its relationships in university students who belong to the age group termed as "emerging adulthood" (i.e., 18 to 29 years; Arnett et al. 2014) in Lithuania. Previous research highlighted that individuals who belong to the emerging adulthood often tend to problematic behavior in different life areas and are vulnerable to mental disorders such as depression and different forms of addiction (Arnett et al. 2014; Sussman and Arnett 2014; World Health Organization 2021). They also tend to experience a high level of daily stress and often try to escape it by intensive use of SM (Primack et al. 2017). Therefore, previous studies described them to be at enhanced risk for the potential negative consequences of SMU and for the development of problematic usage tendencies (e.g., Andreassen et al. 2017; Rozgonjuk et al. 2020). It has been argued that there is an increased need to focus on the mental health of this specific group, to control and to reduce its SMU (Brailovskaia et al. 2020b). However, the available research was conducted outside the Baltic region, specifically Lithuania. Thus, the generalization of earlier findings and conclusions remains unclear (see Schwartz et al. 2001).

Against this background, to avoid speculations because of preliminary findings' lack in this country and to close the described research gap, it should be investigated exploratory whether (1.) the students in Lithuania can be statistically grouped due to their level of problematic SMU. This step should contribute to the assessment of the extent of problematic online behavior in Lithuania. Furthermore, it should be investigated whether (2.) the groups differ due to their level of five variables that previously have been reported to be closely associated with problematic SMU (i.e., SM flow, life satisfaction, depression, anxiety and stress symptoms). The findings could reveal whether intensive SMU should be considered as problematic in Lithuania, and whether Lithuanian emerging adulthood could also benefit from previously suggested prevention steps such as usage control and reduction.

To overcome the problem of findings' comparability and to contribute to potential conclusions on university, it is of advantage to investigate the same hypotheses/research questions with the same instruments at once in different countries (Schwartz et al. 2001). A large proportion of European research on problematic SMU bases on German samples (Brailovskaia and Teichert 2020; Brailovskaia et al. 2020a). Thus, to instantaneously examine whether the result patterns from Lithuania correspond to findings from other countries, additionally to a Lithuanian sample, a German sample was included in the present investigation. Lithuania has a remarkable smaller population than Germany (Stephenson 2018). But on a percentage basis, the popularity of SMU appears to be similar high in both countries (StatCounter GlobalStats 2021a, 2021b).

\section{Materials and Methods}

\section{Procedure and Participants}

Lithuanian Sample The sample comprised 1640 SM users $\left(68.5 \%\right.$ women; $M_{\text {age }}\left(S D_{\text {age }}\right)=19.09$ (1.05), range: $18-29$; all first year undergraduate students), who were recruited by 
face-to-face or online invitation and were provided with the link to the online survey. All university freshmen who enrolled in September 2019 at a large university in Vilnius were invited to participate in the study.

German Sample Data of 727 SM users (75.4\% women; $M_{\text {age }}\left(S D_{\text {age }}\right)=21.47$ (3.02), range: $18-29$; first year undergraduate students: $60.2 \%$, older students (semester two to six): $39.8 \%$ ) were collected by an e-mailed invitation including the link to the online survey that was sent to all freshmen who enrolled in October 2019 at a large university in the German Ruhr region. Additionally, the invitation was sent to a randomly selected group of 500 older students at the same university who had previously agreed to be contacted for research investigations.

Participation in the study was voluntary. The only participation requirement was the membership on at least one social platform. For German students only, participation was compensated by course credits. The present study was approved by the responsible Ethics Committee in Lithuania and in Germany. All participants were properly instructed and gave online their informed consent to participate. The online surveys were provided in the national language of the samples. In both countries, data were collected between October and December 2019.

\section{Measures}

Problematic Social Media Use The brief version of the Bergen Social Media Addiction Scale (BSMAS; Andreassen et al. 2017) assessed the tendency of problematic SMU. This instrument consists of six items representing the six core features of problematic SMU (i.e., salience: "Did you spend a lot of time thinking about Social Media or planned use of Social Media?"; tolerance: "Did you feel an urge to use Social Media more and more?"; mood modification: "Did you use Social Media in order to forget about personal problems?"; relapse: "Did you try to cut down on the use of Social Media without success?"; withdrawal: "Did you become restless or troubled if you have been prohibited from using Social Media?"; conflict: "Did you use Social Media so much that it has had a negative impact on your job/studies?"). Each item is rated on a 5 -point Likert-type scale $(1=$ very rarely, $5=$ very often; current scale reliability: Lithuanian sample: Cronbach's $\alpha=.81$, German sample: $\alpha=.83$ ). Confirmatory Factor Analysis (CFA) of a single-factor model in a full study sample yielded a very good model fit $\left(\chi^{2}(8)=28.62, p<.001, \mathrm{CFI} /\right.$ TLI $=.994 / .988$, RMSEA [90\% CI $]=.033[.020, .046]$, SRMR =.014). Scalar measurement invariance by country was established (see supplementary materials Table S1).

Social Media Flow A modified version of the "Facebook Flow Questionnaire" (FFQ; Brailovskaia et al. 2018; Kwak et al.
2014) was used to assess the SM flow experience. To adapt this instrument to SM, the term "Facebook" was replaced by the term "Social Media". The eleven items are divided into the five online flow subscales: respectively two items belong to the subscale "focused attention" (e.g., "While using Social Media, I am deeply engrossed"), to the subscale "enjoyment" (e.g., "I enjoy using Social Media"), to the subscale "curiosity" (e.g., "Using Social Media arouses my imagination"), and to the subscale "time-distortion (e.g., "Time flies when I am using Social Media"); and three items belong to the subscale "telepresence" ("Social Media create a new world for me, and this world suddenly disappears when I stop browsing"). They are rated on a 5-point Likert-type scale ( $1=$ strongly disagree, $5=$ strongly agree; current scale reliability: Lithuanian sample: $\alpha=.84$, German sample: $\alpha=.86$ ). The five-factor CFA in a full study sample yielded a very good model fit $\left(\chi^{2}(30)=\right.$ 77.47, $p<.001, \mathrm{CFI} / \mathrm{TLI}=.996 / .992, \mathrm{RMSEA}[90 \%$ $\mathrm{CI}]=.025[.018, .032], \mathrm{SRMR}=.014)$; the second-order CFA resulted in an excellent model fit $\left(\chi^{2}(32)=82.52\right.$, $p<.001, \mathrm{CFI} / \mathrm{TLI}=.995 / .991, \mathrm{RMSEA}[90 \% \mathrm{CI}]=.026$ $[.019, .033]$, SRMR $=.015)$. Metric measurement invariance by country was established (see supplementary materials Table S1).

Depression, Anxiety, and Stress Symptoms To assess depression, anxiety, and stress symptoms the Depression Anxiety Stress Scales 21 (DASS-21; Lovibond and Lovibond 1995) was included. The overall 21 items are divided to three subscales. Each subscale consists of seven items (e.g., depression subscale: "I couldn't seem to experience any positive feeling at all"; anxiety subscale: "I felt scared without any good reason"; stress subscale: "I found it difficult to relax") that are rated on a 4-point Likert-type scale $(0=$ did not apply to me at all, 3 =applied to me very much or most of the time; current scale reliability: Lithuanian sample: depression subscale: $\alpha=.90$, anxiety subscale: $\alpha=.84$, stress subscale: $\alpha=.87$; German sample: depression subscale: $\alpha=.92$, anxiety subscale: $\alpha=.86$, stress subscale: $\alpha=.88$ ). The three-factor CFA in a full study sample yielded a good model fit $\left(\chi^{2}(164)=745.73, p<.001, \mathrm{CFI} / \mathrm{TLI}=.974 / .967\right.$, RMSEA $[90 \% \mathrm{CI}]=.039[.036, .042], \mathrm{SRMR}=.025)$. Metric measurement invariance by country was established (see supplementary materials Table S1).

Life Satisfaction Global life satisfaction was assessed with the unidimensional Satisfaction with Life Scale (SWLS; Diener et al. 1985). The five items (e.g., "In most ways, my life is close to my ideal") are rated on a 7-point Likert-type scale ( 1 = strongly disagree, 7 = strongly agree; current scale reliability: Lithuanian sample: $\alpha=.82$, German sample: $\alpha=.91$ ). Single-factor CFA in a full study sample yielded an excellent model fit $\left(\chi^{2}(2)=2.36, p=.307, \mathrm{CFI} / \mathrm{TLI}=1.000 / 1.000\right.$, RMSEA $[90 \% \mathrm{CI}]=[.000, .043], \mathrm{SRMR}=.003)$. Configural 
measurement invariance by country was established (see supplementary materials Table S1).

For all scales higher values indicate higher levels of the assessed construct.

\section{Statistical Analysis}

The descriptive analyses were conducted using SPSS 24, for all other analyses the Mplus 8.2 version (Muthén and Muthén 1998-2017) was used. As a preliminary step, we tested measurement invariance by country for each measure used in the study. We compared the configural models (CFA, allowing the correlations between errors of the same items across countries) with the metric model, in which the factor loadings were constrained to be equal across countries', and the scalar mod$\mathrm{el}$, in which item intercepts were also constrained to be equal across countries. Model comparisons were conducted by examining the changes in fit indices (e.g., Chen 2007).

To classify the study participants due to their level of problematic SMU, we used a Latent Class Analysis (LCA) approach (Muthén and Muthén 2000). We conducted the itemlevel LCA by using the mean scores of salience, tolerance, mood modification, relapse, withdrawal, and conflict, representing the different characteristics of problematic SMU. The LCA analyses resulted in distinguishing the subgroups of the participants with different levels of problematic SMU. We used several statistical criteria to decide on a final number of latent classes (Muthén and Muthén 2000). First, Akaike Information Criterion (AIC) and Bayesian Information Criterion (BIC) statistic for a solution with $\mathrm{k}$ classes should be lower than for a solution with $\mathrm{k}-1$ classes. Second, a statistically significant $p$ value of the adjusted Lo-, Mandel-, and Rubin test, which compares improvement in fit between neighboring class solutions, determined improvement in fit through the inclusion of an additional class. Additionally, in all analyses, we used the Entropy score, with the values equal or above 70 indicative of an accurate classification with higher values representing a better fit. Finally, we accounted for the number of participants in the smallest class which should be not lower than $5 \%$ of the study sample. After identifying the problematic SMU pattern groups, we compared the proportions of the participants in these groups among countries by using the chi-square analysis.

All study variables were approximately normally distributed among all problematic SMU classes, as the coefficients of skewness and kurtosis were within the range of \pm 2 (Gravetter and Wallnau 2014). To compare the distinguished groups in terms of SM flow experiences (the scale as a whole and the subscales, i.e., focused attention, enjoyment, curiosity, telepresence, and time-distortion), as well as the levels of mental health indicators (i.e., depression, anxiety, stress symptoms, and life satisfaction), we tested a series of Structural Equation Models (SEM). For these models, we created dummy variables by coding the participants from a particular problematic SMU group as 1 versus the reference group (participants coded as 0 ), when the participants from all other groups coded as missing. We used these dummy variables as the independent categorical variables in separate analyses and the latent variables of SM flow experiences and the mental health indicators as dependent variables. The differences among pairs of LCA groups in terms of the mental health indicators were tested in a separate model from overall SM flow experiences and SM flow indicators. The conceptual SEM models are presented in supplementary Fig. S1. In all models, we controlled for age and gender effects and allowed correlations between dependent variables. After conducting the SEM analyses in a full study sample, we tested for possible moderating effects of the country and assessed differences between the models with fixed versus free regression parameters. To determine significant differences between the models with fixed versus free parameters, at least two of these three criteria had to be matched: $\Delta \chi^{2}$ significant at $p<.05$ (Satorra and Bentler 2001), $\Delta \mathrm{CFI} \geq .01$, and $\Delta$ RMSEA $\geq .015$ (Chen 2007). As no moderation effects were found, in the results section, we present the findings from the models conducted in a full study sample.

The model fit in CFA and SEM analyses was evaluated by using the Comparative Fit Index (CFI), Tucker-Lewis Index (TLI), and the Root Mean Square Error of Approximation (RMSEA), following the goodness of fit recommendation provided by Kline (2006). Namely, CFI/TLI values higher than .90 indicated an acceptable fit and values higher than .95 represented a very good fit; RMSEA values below .08 indicated of an acceptable fit and values less than .05 suggested a good fit.

\section{Results}

Table 1 presents the descriptive statistics of the investigated variables in a full study sample and in the two countries separately.

\section{Patterns of Problematic SMU}

The results of the LCA analyses indicated that the four-classes model fitted the data best (see supplementary materials Table S2). The patterns of problematic SMU are presented in Fig. 1.

We found that $56.5 \%(n=1,338)$ of the investigated participants belonged to a group with relatively low levels of all problematic SMU characteristics and comparatively low mean sum score of the full problematic SMU scale $(M=9.39, S D=2.21)$, and we labeled this pattern as low-symptom. The second most prevalent pattern, representing $21.9 \%(n=518)$ of the participants was characterized by relatively higher levels of salience and mood modification and low levels of withdrawal symptoms, with moderate scores on the other indicators as well as a 
Table 1 Descriptive statistics of the study variables (overall and in each investigated country separately)

\begin{tabular}{|c|c|c|c|c|c|c|}
\hline & \multicolumn{2}{|c|}{ Total sample, $N=2367$} & \multicolumn{2}{|c|}{$\begin{array}{l}\text { Lithuanian } \\
\text { sample, } n=1640\end{array}$} & \multicolumn{2}{|c|}{$\begin{array}{l}\text { German sample, } \\
n=727\end{array}$} \\
\hline & $M(S D)$ & Min-Max & $M(S D)$ & Min-Max & $M(S D)$ & Min-Max \\
\hline Problematic SMU & $12.89(5.02)$ & $6-30$ & $13.30(5.00)$ & $6-30$ & $11.97(4.94)$ & $6-29$ \\
\hline SM Flow & $32.02(7.30)$ & $11-53$ & $32.45(6.97)$ & $11-53$ & $31.07(7.92)$ & $11-53$ \\
\hline SM Flow: Focused Attention & $5.69(1.87)$ & $2-10$ & $5.87(1.73)$ & $2-10$ & $5.29(2.11)$ & $2-10$ \\
\hline SM Flow: Enjoyment & $6.72(1.68)$ & $2-10$ & $6.62(1.61)$ & $2-10$ & $6.96(1.80)$ & $2-10$ \\
\hline SM Flow: Curiosity & $6.74(1.87)$ & $2-10$ & $6.80(1.78)$ & $2-10$ & $6.61(2.04)$ & $2-10$ \\
\hline SM Flow: Telepresence & $5.89(2.71)$ & $3-15$ & $6.12(2.65)$ & $3-15$ & $5.37(2.77)$ & $3-15$ \\
\hline SM Flow: Time-Distortion & $6.98(2.18)$ & $2-10$ & $7.04(2.12)$ & $2-10$ & $6.84(2.31)$ & $2-10$ \\
\hline Life Satisfaction & $23.60(6.23)$ & $5-35$ & $23.08(5.77)$ & $5-35$ & $24.78(7.03)$ & $5-35$ \\
\hline Depression Symptoms & $6.79(5.57)$ & $0-21$ & $7.33(5.52)$ & $0-21$ & $5.58(5.49)$ & $0-21$ \\
\hline Anxiety Symptoms & $5.81(4.93)$ & $0-21$ & $6.41(4.93)$ & $0-21$ & $4.46(4.65)$ & $0-21$ \\
\hline Stress Symptoms & $9.01(5.28)$ & $0-21$ & $9.61(5.24)$ & $0-21$ & $7.64(5.14)$ & $0-21$ \\
\hline
\end{tabular}

Notes. $M=$ mean, $S D=$ standard deviation, $M i n=$ minimum, $M a x=$ maximum, $\mathrm{SM}=$ social media, $\mathrm{SMU}=$ social media use

moderate mean problematic SMU sum score $(M=16.33, S D=$ 2.40); we labeled this pattern as low-withdrawal. The next pattern shown by $14.4 \%(n=340)$ of the present participants, in contrast, was characterized by high levels of withdrawal symptoms, moderate scores on all other indicators as well as a moderate mean problematic SMU sum score $(M=15.90, S D=2.80)$; we labeled this pattern as high-withdrawal. We chose the labeling low-withdrawal and high-withdrawal because the difference of the withdrawal level was the most striking between both groups. The last pattern, representing the lowest proportion of the study sample (i.e., $7.2 \%, n=171$ ), was characterized by high levels of all problematic SMU indicators as well as a high mean problematic SMU sum score $(M=23.89, S D=2.52)$, and we labeled this pattern as high-symptom.

\section{Problematic SMU Patterns among the Two Study Countries}

The results indicated significant differences between Lithuania and Germany, in terms of proportions of students in the four problematic SMU groups $\left(\chi^{2}(3)=54.51\right.$, $p<.001)$. Specifically, we found that in the Lithuanian sample, a smaller number of participants $(51.8 \%)$ belonged to the low-symptom group, compared to the German sample

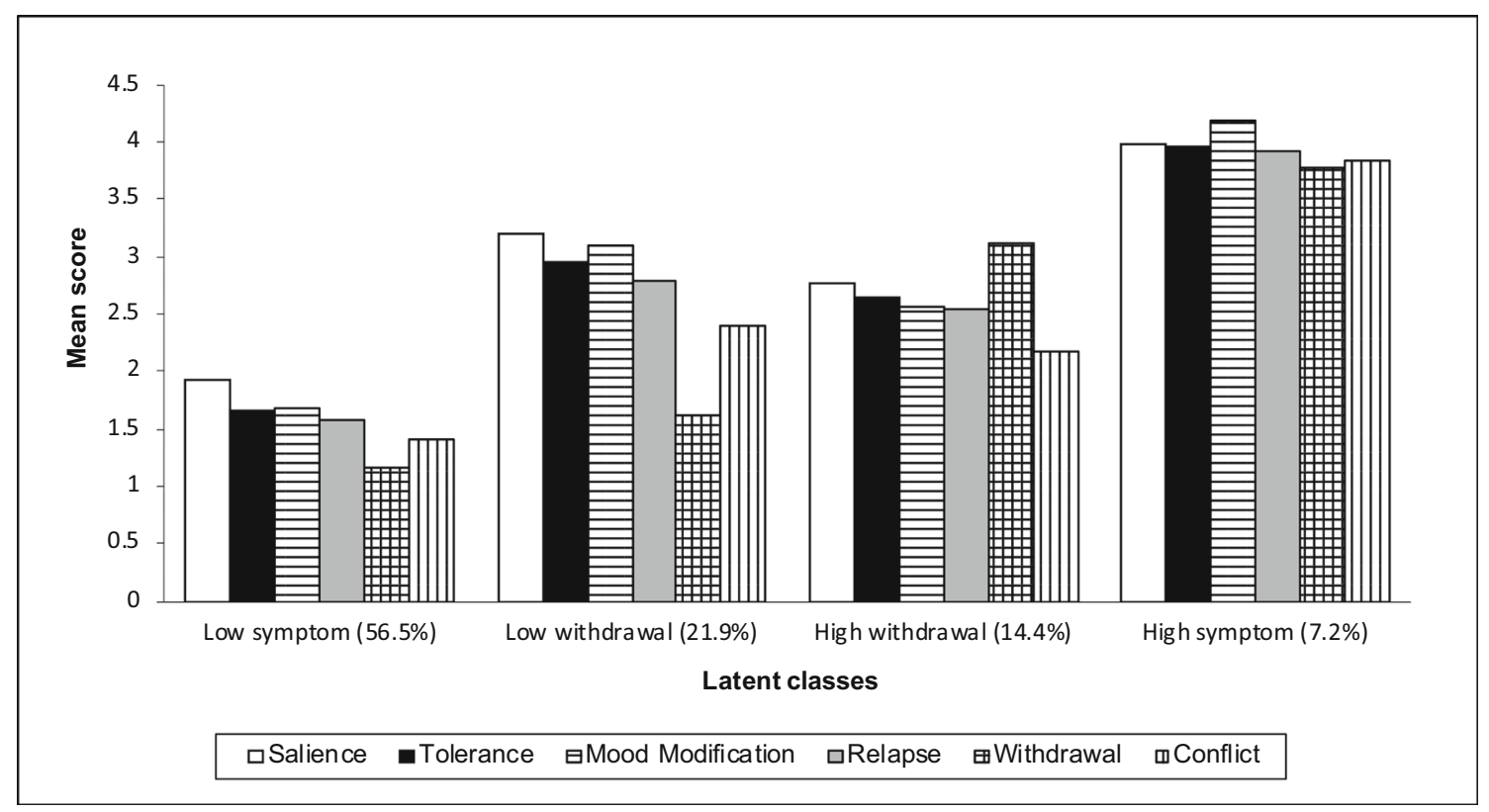

Fig. 1 Latent classes based on problematic social media use indicators (including the levels of the single problematic characteristics in the classes; Lithuanian and German sample combined: $N=2,367$ ) 
(67.1\%, adj. stand. res. $=-6.9)$. Furthermore, more Lithuanian students belonged to the high-withdrawal group (17.0\%) and to the low-withdrawal group (23.7\%), compared to German students $(8.5 \%$, adj. stand. res. $=-5.4$ and $17.7 \%$, adj. stand. res. $=-3.2$ respectively). No significant differences were found among countries in terms of the proportion of students in the high-symptom group (Lithuanian sample: $7.5 \%$; German sample: $6.6 \%$ ).

\section{Associations of Problematic SMU Patterns with SM Flow Experiences}

In the following, results from the SEM models conducted in a full study sample are presented, as no moderating effects of the country were found. The SEM analyses revealed that the identified problematic SMU groups are characterized by different levels of SM flow indicators (see Table 2 and supplementary materials Table S3).

In particular, we found that the low-symptom group, compared to all other groups $(p<.001)$ reported the lowest levels of overall flow $\left(\beta_{\text {low-withdrawal }}=.52 ; \beta_{\text {high-withdrawal }}=.43\right.$; $\left.\beta_{\text {high-symptom }}=.66\right)$, as well as of focused attention $\left(\beta_{\text {low-with- }}\right.$ drawal $\left.=.31 ; \beta_{\text {high-withdrawal }}=.28 ; \beta_{\text {high-symptom }}=.43\right)$, enjoyment $\left(\beta_{\text {low-withdrawal }}=.14 ; \beta_{\text {high-withdrawal }}=.17 ; \beta_{\text {high-symp- }}\right.$ tom $=.19)$, curiosity $\left(\beta_{\text {low-withdrawal }}=.15 ; \beta_{\text {high-withdrawal }}=.17\right.$; $\left.\beta_{\text {high-symptom }}=.18\right)$, telepresence $\left(\beta_{\text {low-withdrawal }}=.47 ; \beta_{\text {high- }}\right.$ withdrawal $\left.=.40 ; \beta_{\text {high-symptom }}=.65\right)$, and time-distortion $\left(\beta_{\text {low- }}\right.$ withdrawal $=.40 ; \beta_{\text {high-withdrawal }}=.30 ; \beta_{\text {high-symptom }}=.45$ ).

The high-symptom group, compared to the low-withdrawal and high-withdrawal groups, reported higher levels of overall flow $\left(\beta_{\text {low-withdrawal }}=-.68, p<.001 ; \beta_{\text {high-withdrawal }}=-.77\right.$, $p<.001)$, as well as of focused attention $\left(\beta_{\text {low-withdrawal }}=\right.$ $\left.-.38, p<.001 ; \beta_{\text {high-withdrawal }}=-.39, p<.001\right)$, enjoyment $\left(\beta_{\text {low-withdrawal }}=-.17, p<.001 ; \beta_{\text {high-withdrawal }}=-.12\right.$, $p=.034)$, telepresence $\left(\beta_{\text {low-withdrawal }}=-.44, p<.001 ; \beta_{\text {high- }}\right.$ withdrawal $=-.50, p<.001)$, and time-distortion $\left(\beta_{\text {low-withdraw- }}\right.$ al $\left.=-.38, p<.001 ; \beta_{\text {high-withdrawal }}=-.47, p<.001\right)$.

Additionally, the high-symptom group reported higher levels of curiosity $(\beta=-.16, p<.001)$, compared to the lowwithdrawal group, with no differences in curiosity among high-symptom and high-withdrawal groups. Moreover, the high-withdrawal group, compared to the low-withdrawal group, reported higher levels of curiosity $\left(\beta_{\text {low-withdrawal }}=\right.$ $-.08, p=.045)$ and enjoyment $\left(\beta_{\text {low-withdrawal }}=-.08\right.$, $p=.041)$, and lower levels of time-distortion ( $\beta_{\text {low-withdrawal }}$ $=.09, p=.025$ ), with no differences among these groups in terms of focused attention and telepresence.

\section{Associations of Problematic SMU Patterns with Mental Health}

The SEM analyses revealed that the identified problematic SMU groups are characterized by different levels of the mental health indicators (see Table 2 and supplementary materials Table S3). In particular, we found that the low-symptom group, compared to all other groups $(p<.001)$, reported the lowest levels of depression $\left(\beta_{\text {low-withdrawal }}=.20 ; \beta_{\text {high-withdraw- }}\right.$ $\left.{ }_{\mathrm{al}}=.16 ; \beta_{\text {high-symptom }}=.34\right)$, anxiety $\left(\beta_{\text {low-withdrawal }}=.21\right.$; $\left.\beta_{\text {high-withdrawal }}=.20 ; \beta_{\text {high-symptom }}=.38\right)$, and stress symptoms $\left(\beta_{\text {low-withdrawal }}=.23 ; \beta_{\text {high-withdrawal }}=.21 ; \beta_{\text {high-symptom }}=.33\right)$, as well as the highest levels of life satisfaction ( $\beta_{\text {low-withdraw- }}$ $\left.\mathrm{al}=-.15 ; \beta_{\text {high-withdrawal }}=-.13 ; \beta_{\text {high-symptom }}=-.23\right)$.

The high-symptom group, compared to low-withdrawal and high-withdrawal groups $(p<.001)$, reported higher levels of depression $\left(\beta_{\text {low-withdrawal }}=-.26 ; \beta_{\text {high-withdrawal }}=-.31\right)$, anxiety $\left(\beta_{\text {low-withdrawal }}=-.29 ; \beta_{\text {high-withdrawal }}=-.31\right)$, and stress symptoms $\left(\beta_{\text {low-withdrawal }}=-.24 ; \beta_{\text {high-withdrawal }}=\right.$ $-.26)$, as well as lower levels of life satisfaction $\left(\beta_{\text {low- }}\right.$

Table 2 Mean sum scores of the study variables in the problematic SMU groups

\begin{tabular}{|c|c|c|c|c|c|c|c|c|}
\hline & \multicolumn{2}{|c|}{ Low-Symptom $(n=1338)$} & \multicolumn{2}{|c|}{ Low-Withdrawal $(n=518)$} & \multicolumn{2}{|c|}{ High-Withdrawal $(n=340)$} & \multicolumn{2}{|c|}{ High-Symptom $(n=171)$} \\
\hline & $M$ & $S D$ & $M$ & $S D$ & $M$ & $S D$ & $M$ & $S D$ \\
\hline SM Flow & $28.76^{\mathrm{a}}$ & 6.24 & $35.24^{\mathrm{b}}$ & 5.22 & $35.26^{\mathrm{b}}$ & 5.78 & $41.43^{\mathrm{c}}$ & 6.54 \\
\hline SM Flow: Focused Attention & $5.06^{\mathrm{a}}$ & 1.77 & $6.28^{\mathrm{b}}$ & 1.59 & $6.34^{\mathrm{b}}$ & 1.58 & $7.57^{\mathrm{c}}$ & 1.67 \\
\hline SM Flow: Enjoyment & $6.40^{\mathrm{a}}$ & 1.70 & $6.98^{\mathrm{b}}$ & 1.50 & $7.17^{\mathrm{c}}$ & 1.50 & $7.58^{\mathrm{d}}$ & 1.78 \\
\hline SM Flow: Curiosity & $6.38^{\mathrm{a}}$ & 1.96 & $7.06^{\mathrm{b}}$ & 1.61 & $7.28^{\mathrm{c}}$ & 1.60 & $7.55^{\mathrm{c}}$ & 1.72 \\
\hline SM Flow: Telepresence & $4.79^{\mathrm{a}}$ & 1.98 & $6.96^{\mathrm{b}}$ & 2.58 & $6.78^{\mathrm{b}}$ & 2.57 & $9.53^{\mathrm{c}}$ & 3.14 \\
\hline SM Flow: Time-Distortion & $6.13^{\mathrm{a}}$ & 2.14 & $7.96^{\mathrm{b}}$ & 1.62 & $7.69^{\mathrm{c}}$ & 1.78 & $9.19^{\mathrm{d}}$ & 1.16 \\
\hline Depression Symptoms & $5.55^{\mathrm{a}}$ & 5.09 & $7.90^{\mathrm{b}}$ & 5.54 & $7.67^{\mathrm{b}}$ & 5.47 & $11.42^{\mathrm{c}}$ & 6.03 \\
\hline Anxiety Symptoms & $4.57^{\mathrm{a}}$ & 4.30 & $6.82^{\mathrm{b}}$ & 4.90 & $6.96^{\mathrm{b}}$ & 4.89 & $10.25^{\mathrm{c}}$ & 5.83 \\
\hline Stress Symptoms & $7.55^{\mathrm{a}}$ & 4.90 & $10.33^{\mathrm{b}}$ & 5.12 & $10.58^{\mathrm{b}}$ & 4.84 & $13.29^{\mathrm{c}}$ & 5.22 \\
\hline Life Satisfaction & $24.57^{\mathrm{a}}$ & 6.12 & $22.66^{\mathrm{b}}$ & 5.79 & $22.89^{\mathrm{b}}$ & 6.03 & $20.30^{\mathrm{c}}$ & 7.06 \\
\hline
\end{tabular}

Notes. $M=$ mean, $S D=$ standard deviation, $\mathrm{SM}=$ social media; ${ }^{\mathrm{a}, \mathrm{b}, \mathrm{c}, \mathrm{d}}=$ different letters indicate significant differences 
withdrawal $=.18 ; \beta_{\text {high-withdrawal }}=.20$ ). No differences were found among the high-withdrawal and low-withdrawal groups.

\section{Discussion}

Social media use belongs to everyday life of many people around the globe (Chaffey 2020). Especially young students who belong to the age group termed as emerging adulthood tend to intensive online behavior when they strive for positive emotions and distraction (Brailovskaia et al. 2020a). Currently, the relationship of this behavior with users' mental health is the topic of critical debate. While some researchers warn of potential negative consequences of the online activity (Brailovskaia et al. 2020b; Griffiths 2019), others request not to overestimate its impact on mental health (Carbonell and Panova 2017). The current study could at least partly contribute to the clarification of the critical discussion on problematic SMU, as it provides one of the first findings on problematic SMU and its relationships from the Baltic region, specifically from Lithuanian emerging adulthood. Notably, previous research described this age group to be at enhanced risk for problematic SMU (Marino et al. 2018b) and for mental disorders (Sussman and Arnett 2014). In addition, the findings are compared to those of a German student sample. While the main result patterns were similar in both countries, some specific findings differed between the Lithuanian and the German sample. This emphasizes the need for cautiousness when drawing conclusions on generalizability due to problematic SMU, as well as the need for further cross-national investigations to clarify the critical debate.

In the Lithuanian sample, the mean score of problematic SMU (see Table 1) was significantly higher than the mean score in the German sample $(t(2365)=5.97, p<.001)$. Moreover, it exceeded the score reported by earlier research from Norway that used the same instrument to assess problematic SMU $(M=10.30$; Andreassen et al. 2016). Thus, problematic SMU seems to be a relevant issue in the Lithuanian student population. This finding corresponds to previous results that emphasized the enhanced significance of pathological Internet use in Lithuanian young adults and adolescents in the last years (Ustinavičienè et al. 2016).

After the analysis of the mean scores of problematic SMU, we investigated exploratory whether the students from Lithuania and Germany can be grouped considering their problematic SMU level. Our findings reveal that in both countries the four groups classification fits the data best: lowsymptom, low-withdrawal, high-withdrawal, and highsymptom. More than the half of the full sample that included data from both countries was grouped to low-symptom. People who belong to this group seem to use SM without problematic tendencies. It might be hypothesized that in stressful situations they typically tend to functional coping strategies and do not consider the online world as a possibility to escape the negative experiences (Ryan et al. 2014). This could provide them the possibility to use the advantage of the online world (e.g., gain of information, inspiration and interaction) and reduce the tendency for problematic SMU (Duradoni et al. 2020). A comparison between both countries, revealed that the proportion of such individuals was significantly lower in Lithuania than in Germany. The cross-sectional design of the present study does not allow true conclusion on causality. Therefore, based on the current findings, it can only be hypothesized that Lithuanian students might be at a higher risk for problematic SMU than German students.

About one fifth of the full sample was classified as lowwithdrawal. The mean score of problematic SMU in this group was comparatively high in comparison to the group low-symptom which can be partly explained by the enhanced levels of salience and mood modification. It seems that an important reason for SMU of individuals who belong to the group low-withdrawal is the search for positive emotions, fun and entertainment in the online world that can improve their mood state (Brailovskaia et al. 2020a). The more positive emotions they gain on SM, the higher might be the probability that they will further engage in intensive online activities, and the higher might be the probability for problematic tendencies (Ryan et al. 2014). However, in contrast to the groups highwithdrawal and high-symptom, members of this group are characterized by low levels of withdrawal. Withdrawal describes the physical and psychological unease and nervousness when the online world has to be temporarily left. It is an important component of problematic tendencies that can cause the most negative experiences in individuals concerned (Griffiths 2005). Thus, even though members of the lowwithdrawal group have elevated mean scores of problematic SMU, they might suffer less from their problematic online behavior than members of the other two groups.

Interestingly, the individuals who belonged to the group high-withdrawal - with $14.4 \%$ a rather small part of the full sample - were characterized by moderate levels of the other five problematic SMU subscales. Thus, it can be hypothesized that the physical and psychological unease dominates their thoughts and behavior towards SM rather than for example the search for positive emotions. The comparison of both countries revealed a higher proportion in both groups (lowwithdrawal and high-withdrawal) in the Lithuanian sample than in the German sample.

The fourth group was labeled as high-symptom. This was the comparatively smallest group that included $7.2 \%$ of the full sample. The Lithuanian sample consisted of slightly more participants who belonged to this group than the German sample. But this difference was not significant. In the full sample, the mean score of problematic SMU of the high-symptom group was more than twice as high as the mean score of the 
low-symptom group. Also, it was higher than the mean score of the group low-withdrawal and of the group highwithdrawal. As shown in Fig. 1, the levels of all six characteristics were in this group remarkably high.

The presented findings go beyond the simplified consideration of the mean scores only. They show a potential way how individuals might be grouped due to their specific composition of the problematic characteristics, and thus reveal a better understanding of different potential manifestations of problematic SMU especially in the emerging adulthood. Moreover, they demonstrate that despite the significant higher mean score of problematic SMU in the Lithuanian sample, both countries do not significantly differ considering the high-risk group (i.e., high-symptom group).

The four identified groups partly differed due to their levels of online flow and the variables of mental health. Considering the same result patterns in Lithuania and in Germany and the lacking moderation effects by the variable country, these findings are presented in a full study sample that includes participants from both countries. Earlier research that focused on online gaming and Facebook activity described problematic use tendencies to be positively predicted by intensive use of the online world that is accompanied by the experience of joy and happiness - a state termed as online flow (Brailovskaia et al. 2018; Wu et al. 2013; Trivedi and Teichert 2017). The wish to prolong the positive flow experience was described to contribute to the strong need to continue the online behavior, despite potential negative consequences, such as conflicts in the offline world that are caused by the high usage time and the neglect of daily obligations, and to foster the problematic use tendencies (Brailovskaia et al. 2020a). In the present study, the group low-symptom had the lowest level of flow experienced during SMU (SM flow as a construct and all subscales), while the group high-symptom had the highest level of flow (SM flow as a construct and most of its subscales). Thus, it can be hypothesized that individuals who experience less flow during SMU might tend to less problematic SMU.

Furthermore, the low-symptom group had the highest levels of mental health in comparison to the other three groups. Its members had the lowest levels of the negative mental health indicators (i.e., depression, anxiety and stress symptoms), and the highest level of the positive mental health indicator (i.e., life satisfaction). In contrast, the high-symptom group had the lowest levels of mental health. Previous studies reported problematic SMU to be positively related to the indicators of negative mental health (e.g., Atroszko et al. 2018; Boursier et al. 2020a; Marino et al. 2018b). Its association with positive mental health indicators was negative (Błachnio et al. 2016; Longobardi et al. 2020). As revealed by present results, these associations are also true for students in Lithuania.

Our findings show that it is reasonable to distinguish groups due to their levels of problematic SMU characteristics.
The groups differ considering the levels of the mental health variables. Both withdrawal groups seem to have an intermediate position. They have an enhanced mean score of problematic SMU and enhanced levels of depression, anxiety and stress symptoms, as well as a decreased level of life satisfaction in comparison to the low-symptom group (see Table 2). However, their levels of the negative mental health indicators are below the levels of the high-symptom group. And their indicator of positive mental health is higher than the one of the high-symptom group. Thus, if we assume that problematic SMU is an issue of cross-national importance and not only a marginal phenomenon - which is currently critically discussed (Carbonell and Panova 2017) - the question arises whether the withdrawal groups could be a developmental interim step between both the healthy (low-symptom group) and the unhealthy (high-symptom group) online behavior. Lowwithdrawal might be the preliminary stage of highwithdrawal that might be the preliminary stage of highsymptom, or both withdrawal manifestations might be coexistent as two potential preliminary stages of high-symptom. Considering the cross-sectional design of the present study, this question cannot be answered by our findings. But our findings can serve as the framework for future longitudinal and experimental studies in this context.

Notably, one single study cannot completely answer the question whether problematic SMU should be considered as a serious risk for mental health. Thus, it remains a topic of critical discussion. However, it should be noted that available research revealed experimental evidence that a controlled reduction of time spent on SM can be of benefit for mental health (Brailovskaia et al. 2020b; Hunt et al. 2018). A recent study described potential strategies for self-control of SMU such as the conscious cognitive control of the own use habits, modification of technical devices to better control the own time spent on SMU, and limitation of daily physical and perceptual access to SM. Individuals who had significant difficulties to realize the strategies had enhanced levels of problematic SMU (Brevers and Turel 2019). Our present classification system might contribute to an extension of this finding. It could be hypothesized that especially people who belong to the high-symptom group have a low level of SMU self-control and therefore might benefit the most from external control. Their family and close friends could support them by monitoring the time they spent online. For example, their parents or partner could keep their technical devices in the evenings or after a previously specified usage time has been exceeded in a safe place. After the problematic characteristics decrease, they could train the SMU self-control. In contrast, individuals who belong to the withdrawal groups could directly have success with a contentious training of the self-control of SMU. If the withdrawal groups are the preliminary stages of the highsymptom group, this training could contribute to the prevention of the transition to the next stage. 
Despite its innovative character for the Baltic region, the present study has some limitations that are important to mention. First, the cross-sectional nature of current data does not allow conclusions on causality of the demonstrated relationships. Future longitudinal experimental studies are necessary for real causal conclusions. Second, despite the large sample sizes, the young and in a large part female composition of the investigated groups that were collected at the same campus respectively in Lithuania and in Germany limits the representativeness of the present results. Therefore, a replication of the current findings in more representative samples in both countries is desirable. Thereby, we recommend to match the samples from both countries accurately considering their demographics to improve their comparability. Moreover, cultural (e.g., collectivism/individualism, dependent/independent self-construal; see Hofstede 2001) and country-specific issues that might impact the assessed variables (e.g., living environment) should be included as control variables. Even though previous research described a cultural closeness between Lithuania and Germany (Balcytiene 2012), the impact of potential differences of culture- and country-specific issues can only be ruled out by the assessment and control of the relevant factors. Third, considering that data were collected by selfreport measures that are prone to social desirability, future studies on problematic SMU are recommended to additionally assess the tendency of social desirability and to control for it in the calculations. Fourth, considering that in the present study the focus was on problematic social media use in general conclusions on specific social platforms should be drawn with caution. Future research is recommended to investigate whether the current findings can be replicated on specific platforms such as Facebook, Instagram or Twitter. Fifth, in the present study, the association of problematic SMU with SM flow, life satisfaction, depression, anxiety and stress symptoms was assessed. To further investigate the suggested classification pattern, future studies are recommended to focus on further variables that were previously reported to be linked to problematic SMU (e.g., attachment style, insomnia; Brailovskaia et al. 2019; D'Arienzo et al. 2019).

To conclude, the present results show that problematic SMU is a relevant topic in Lithuania, specifically in Lithuanian emerging adulthood. Furthermore, the results that correspond in the Lithuanian and in the German sample - reveal that people can be classified to four groups considering their manifestation of characteristics of problematic SMU. The level of mental health significantly differs between the four groups. Our classification allows the following theoretical consideration on the current debate about problematic SMU that requires further empirical investigation. The warning of negative impact of excessive SMU on mental health could be of benefit for individuals in the high-symptom group, while it might be less relevant for individuals in the lowsymptom group. Individuals in both withdrawal groups should not be pathologized but could benefit of enhanced SMU selfcontrol as a kind of prevention strategy.

Supplementary Information The online version contains supplementary material available at https://doi.org/10.1007/s12144-021-01711-w.

Funding Open Access funding enabled and organized by Projekt DEAL.

Data Availability The dataset and further material analysed during the current study will be available from the corresponding author on reasonable request.

\section{Declarations}

Ethical Approval The responsible Ethics Committees approved the present study.

Consent to Participate All participants were properly instructed and gave online their informed consent to participate.

Consent for Publication All participants were properly instructed that data gained in the present study will be used for publication in an anonymous form and gave online their informed consent for publication.

Conflicts of Interest/Competing Interests On behalf of all authors, the corresponding author states that there are no conflicts of interest or competing interests.

\section{References}

American Psychiatric Association. (2013). Diagnostic and statistical manual of mental disorders. Author.

Andreassen, C. S., Billieux, J., Griffiths, M. D., Kuss, D. J., Demetrovics, Z., Mazzoni, E., \& Pallesen, S. (2016). The relationship between addictive use of social media and video games and symptoms of psychiatric disorders: A large-scale cross-sectional study. Psychology of Addictive Behaviors, 30(2), 252-262. https://doi. org/10.1037/adb0000160.

Andreassen, C. S., Griffiths, M. D., Gjertsen, S. R., Krossbakken, E., Kvam, S., \& Pallesen, S. (2013). The relationships between behavioral addictions and the five-factor model of personality. Journal of Behavioral Addictions, 2(2), 90-99. https://doi.org/10.1556/JBA.2. 2013.003.

Andreassen, C. S., Pallesen, S., \& Griffiths, M. D. (2017). The relationship between addictive use of social media, narcissism, and self-esteem: Findings from a large national survey. Addictive Behaviors, 64, 287 293. https://doi.org/10.1016/j.addbeh.2016.03.006.

Arnett, J. J., Žukauskienè, R., \& Sugimura, K. (2014). The new life stage of emerging adulthood at ages 18-29 years: Implications for mental health. The Lancet Psychiatry, 1(7), 569-576. https://doi.org/10. 1016/S2215-0366(14)00080-7.

Atroszko, P. A., Balcerowska, J. M., Bereznowski, P., Biernatowska, A., Pallesen, S., \& Andreassen, C. S. (2018). Facebook addiction among polish undergraduate students: Validity of measurement and relationship with personality and well-being. Computers in Human Behavior, 85, 329-338. https://doi.org/10.1016/j.chb.2018.04.001.

Balcytiene, A. (2012). Culture as a guide in theoretical explorations of Baltic media. In D. C. Hallin \& P. Mancini (Eds.), Comparing 
media systems beyond the Western world (pp. 51-71). Cambridge University Press.

Berryman, C., Ferguson, C. J., \& Negy, C. (2018). Social media use and mental health among young adults. Psychiatric Quarterly, 89(2), 307-314. https://doi.org/10.1007/s11126-017-9535-6.

Billieux, J., Schimmenti, A., Khazaal, Y., Maurage, P., \& Heeren, A. (2015). Are we overpathologizing everyday life? A tenable blueprint for behavioral addiction research. Journal of Behavioral Addictions, 4(3), 119-123.

Błachnio, A., \& Przepiórka, A. (2018). Facebook intrusion, fear of missing out, narcissism, and life satisfaction: A cross-sectional study. Psychiatry Research, 259, 514-519. https://doi.org/10.1016/j. psychres.2017.11.012.

Błachnio, A., Przepiorka, A., \& Pantic, I. (2016). Association between Facebook addiction, self-esteem and life satisfaction: A crosssectional study. Computers in Human Behavior, 55, 701-705. https://doi.org/10.1016/j.chb.2015.10.026.

Boursier, V., Gioia, F., \& Griffiths, M. D. (2020a). Do selfie-expectancies and social appearance anxiety predict adolescents' problematic social media use? Computers in Human Behavior, 110, 106395. https://doi.org/10.1016/j.chb.2020.106395.

Boursier, V., Gioia, F., Musetti, A., \& Schimmenti, A. (2020b). Facing loneliness and anxiety during the COVID-19 isolation: The role of excessive social media use in a sample of Italian adults. Frontiers in Psychiatry, 11. https://doi.org/10.3389/fpsyt.2020.586222.

Brailovskaia, J., \& Margraf, J. (2017). Facebook addiction disorder (FAD) among German students - A longitudinal approach. PLoS One, 12(12), e0189719. https://doi.org/10.1371/journal.pone. 0189719.

Brailovskaia, J., Rohmann, E., Bierhoff, H.-W., \& Margraf, J. (2018). The brave blue world: Facebook flow and Facebook addiction disorder (FAD). PLoS One, 13(7), e0201484. https://doi.org/10.1371/ journal.pone.0201484.

Brailovskaia, J., Rohmann, E., Bierhoff, H.-W., Margraf, J., \& Köllner, V. (2019). Relationships between addictive Facebook use, depressiveness, insomnia, and positive mental health in an inpatient sample: A German longitudinal study. Journal of Behavioral Addictions, 8(4), 703-713. https://doi.org/10.1556/2006.8.2019.63.

Brailovskaia, J., Schillack, H., \& Margraf, J. (2020a). Tell me why are you using social media (SM)! Relationship between reasons for use of SM, SM flow, daily stress, depression, anxiety, and addictive SM use-an exploratory investigation of young adults in Germany. Computers in Human Behavior, 113, 106511. https://doi.org/10. 1016/j.chb.2020.106511.

Brailovskaia, J., Ströse, F., Schillack, H., \& Margraf, J. (2020b). Less Facebook use-more well-being and a healthier lifestyle? An experimental intervention study. Computers in Human Behavior, 108, 106332. https://doi.org/10.1016/j.chb.2020.106332.

Brailovskaia, J., \& Teichert, T. (2020). "I like it" and "I need it": Relationship between implicit associations, flow, and addictive social media use. Computers in Human Behavior, 13, 106509. https:// doi.org/10.1016/j.chb.2020.106509.

Brailovskaia, J., Teismann, T., \& Margraf, J. (2020c). Positive mental health mediates the relationship between Facebook addiction disorder and suicide-related outcomes: A longitudinal approach. Cyberpsychology, Behavior and Social Networking, 23(5), 346350. https://doi.org/10.1089/cyber.2019.0563.

Brevers, D., \& Turel, O. (2019). Strategies for self-controlling social media use: Classification and role in preventing social media addiction symptoms. Journal of Behavioral Addictions, 8(3), 554-563. https://doi.org/10.1556/2006.8.2019.49.

Buda, G., Lukoševičiūtè, J., Šalčiūnaite, L., \& Šmigelskas, K. (2020). Possible effects of social media use on adolescent health behaviors and perceptions. Psychological Reports, 0033294120922481. https://doi.org/10.1177/0033294120922481,003329412092248.
Burrow, A. L., \& Rainone, N. (2017). How many likes did I get?: Purpose moderates links between positive social media feedback and selfesteem. Journal of Experimental Social Psychology, 69, 232-236.

Carbonell, X., \& Panova, T. (2017). A critical consideration of social networking sites' addiction potential. Addiction Research \& Theory, 25(1), 48-57.

Casale, S., \& Fioravanti, G. (2018). Why narcissists are at risk for developing Facebook addiction: The need to be admired and the need to belong. Addictive Behaviors, 76, 312-318. https://doi.org/10.1016/j. addbeh.2017.08.038.

Chaffey, D. (2020). Global social media research summery 2020. Smart Insights. https://www.smartinsights.com/social-media-marketing/ social-media-strategy/new-global-social-media-research/.

Chen, F. F. (2007). Sensitivity of goodness of fit indexes to lack of measurement invariance. Structural Equation Modeling, 14(3), 464-504. https://doi.org/10.1080/10705510701301834.

Coyne, S. M., Rogers, A. A., Zurcher, J. D., Stockdale, L., \& Booth, M. (2020). Does time spent using social media impact mental health?: An eight year longitudinal study. Computers in Human Behavior, 104, 106160. https://doi.org/10.1016/j.chb.2019.106160.

Csikszentmihalyi, M. (1990). Flow: The psychology of optimal performance. Cambridge UniversityPress.

D'Arienzo, M. C., Boursier, V., \& Griffiths, M. D. (2019). Addiction to social media and attachment styles: A systematic literature review. International Journal of Mental Health and Addiction, 17(4), 1094 1118. https://doi.org/10.1007/s11469-019-00082-5.

Diener, E., Emmons, R. A., Larsen, R. J., \& Griffin, S. (1985). The satisfaction with life scale. Journal of Personality Assessment, 49(1), 71-75. https://doi.org/10.1207/s15327752jpa4901 13.

Duradoni, M., Innocenti, F., \& Guazzini, A. (2020). Well-being and social media: A systematic review of Bergen addiction scales. Future Internet, 12(2), 24. https://doi.org/10.3390/fi12020024.

Gravetter, F., \& Wallnau, L. (2014). Essentials of statistics for the behavioral sciences (8th ed.). Belmont: Wadsworth.

Griffiths, M. D. (2005). A 'components' model of addiction within a biopsychosocial framework. Journal of Substance Use, 10(4), 191-197. https://doi.org/10.1080/14659890500114359.

Griffiths, M. D. (2019). The evolution of the'components model of addiction'and the need for a confirmatory approach in conceptualizing behavioral addictions. Düşünen Adam: The Journal of Psychiatry and Neurological Sciences, 32, 179-184. https://doi. org/10.14744/DAJPNS.2019.00027.

Habihirwe, P., Porovecchio, S., Bramboiu, I., Ciobanu, E., Croituru, C., Cazacu, I., et al. (2018). Depression, anxiety and stress among college students in three European countries. European Journal of Public Health, 28(suppl_4), cky214-026.

Hofstede, G. (2001). Culture's consequences: Comparing values, behaviors, institutions, and organizations across nations. Sage Publications.

Hunt, M. G., Marx, R., Lipson, C., \& Young, J. (2018). No more FOMO: Limiting social media decreases loneliness and depression. Journal of Social and Clinical Psychology, 37(10), 751-768. https://doi.org/ 10.1521/jscp.2018.37.10.751.

Keyes, C. L. (2005). Mental illness and/or mental health? Investigating axioms of the complete state model of health. Journal of Consulting and Clinical Psychology, 73(3), 539-548. https://doi.org/10.1037/ 0022-006X.73.3.539.

Kircaburun, K., Griffiths, M. D., \& Billieux, J. (2020). Childhood emotional maltreatment and problematic social media use among adolescents: The mediating role of body image dissatisfaction. International Journal of Mental Health and Addiction, 18(6), 1536-1547. https://doi.org/10.1007/s11469-019-0054-6.

Kline, R. B. (2006). Principles and practices of structural equation modeling (2nd ed.). Guilford Press.

Koc, M., \& Gulyagci, S. (2013). Facebook addiction among Turkish college students: The role of psychological health, demographic, and usage 
characteristics. Cyberpsychology, Behavior and Social Networking, 16(4), 279-284. https://doi.org/10.1089/cyber.2012.0249.

Kwak, K. T., Choi, S. K., \& Lee, B. G. (2014). SNS flow, SNS selfdisclosure and post hoc interpersonal relations change: Focused on Korean Facebook user. Computers in Human Behavior, 31, 294 304. https://doi.org/10.1016/j.chb.2013.10.046.

Longobardi, C., Settanni, M., Fabris, M. A., \& Marengo, D. (2020). Follow or be followed: Exploring the links between Instagram popularity, social media addiction, cyber victimization, and subjective happiness in Italian adolescents. Children and Youth Services Review, 113, 104955. https://doi.org/10.1016/j.childyouth.2020. 104955.

Longstreet, P., \& Brooks, S. (2017). Life satisfaction: A key to managing internet \& social media addiction. Technology in Society, 50, 73-77. https://doi.org/10.1016/j.techsoc.2017.05.003.

Lovibond, P. F., \& Lovibond, S. H. (1995). The structure of negative emotional states: Comparison of the depression anxiety stress scales (DASS) with the Beck depression and anxiety inventories. Behaviour Research and Therapy, 33(3), 335-343. https://doi.org/ 10.1016/0005-7967(94)00075-U.

Marengo, D., Montag, C., Sindermann, C., Elhai, J. D., \& Settanni, M. (2021). Examining the links between active Facebook use, received likes, self-esteem and happiness: A study using objective social media data. Telematics and Informatics, 58, 101523. https://doi. org/10.1016/j.tele.2020.101523.

Marino, C., Gini, G., Vieno, A., \& Spada, M. M. (2018a). The associations between problematic Facebook use, psychological distress and well-being among adolescents and young adults: A systematic review and meta-analysis. Journal of Affective Disorders, 226, 274 281. https://doi.org/10.1016/j.jad.2017.10.007.

Marino, C., Gini, G., Vieno, A., \& Spada, M. M. (2018b). A comprehensive meta-analysis on problematic Facebook use. Computers in Human Behavior, 83, 262-277. https://doi.org/10.1016/j.chb.2018. 02.009

Mauri, M., Cipresso, P., Balgera, A., Villamira, M., \& Riva, G. (2011). Why is Facebook so successful? Psychophysiological measures describe a core flow state while using Facebook. Cyberpsychology, Behavior and Social Networking, 14(12), 723-731. https://doi.org/ 10.1089/cyber.2010.0377.

Muthén, B. O., \& Muthén, L. K. (2000). Integrating person-centered and variable-centered analyses: Growth mixture modeling with latent trajectory classes. Alcoholism: Clinical and Experimental Research, 24(6), 882-891. https://doi.org/10.1111/j.1530-0277. 2000.tb02070.x.

Muthén, L. K., \& Muthén, B. O. (1998-2017). Mplus User's Guide (8th ed.). Muthén \& Muthén.

Orben, A., \& Przybylski, A. K. (2019). The association between adolescent well-being and digital technology use. Nature Human Behaviour, 3(2), 173-182. https://doi.org/10.1038/s41562-018-0506-1.

Pew Research Center (2019). Social Media Fact Sheet. https://www. pewresearch.org/internet/fact-sheet/social-media/.

Pribeanu, C., Balog, A., Lamanauskas, V., \& Šlekienè, V. (2015). Social capital on Facebook as perceived by Lithuanian university students: A multidimensional perspective. Journal of Baltic Science Education, 14, 132-141.

Primack, B. A., Shensa, A., Escobar-Viera, C. G., Barrett, E. L., Sidani, J. E., Colditz, J. B., \& James, A. E. (2017). Use of multiple social media platforms and symptoms of depression and anxiety: A nationally-representative study among US young adults. Computers in Human Behavior, 69, 1-9. https://doi.org/10.1016/j. chb.2016.11.013

Rozgonjuk, D., Sindermann, C., Elhai, J. D., Christensen, A. P., \& Montag, C. (2020). Associations between symptoms of problematic smartphone, Facebook, WhatsApp, and Instagram use: An item- level exploratory graph analysis perspective. Journal of Behavioral Addictions, 9(3), 686-697. https://doi.org/10.1556/ 2006.2020.00036.

Ryan, T., Chester, A., Reece, J., \& Xenos, S. (2014). The uses and abuses of Facebook: A review of Facebook addiction. Journal of Behavioral Addictions, 3(3), 133-148. https://doi.org/10.1556/ JBA.3.2014.016.

Satorra, A., \& Bentler, P. (2001). A scaled difference chi-square test statistic for moment structure analysis. Psychometrika, 66(4), 507514.

Schwartz, S. H., Melech, G., Lehmann, A., Burgess, S., Harris, M., \& Owens, V. (2001). Extending the cross-cultural validity of the theory of basic human values with a different method of measurement. Journal of Cross-Cultural Psychology, 32(5), 519-542. https://doi. org/10.1177/0022022101032005001.

StatCounter GlobalStats (2021a). Social Media Stats Germany. https://gs. statcounter.com/social-media-stats/all/germany.

StatCounter GlobalStats (2021b). Social Media Stats Lithuania. https:// gs.statcounter.com/social-media-stats/all/lithuania.

Stephenson, A. V. (2018). The impact of personal income tax structure on income inequality for Belgium, Bulgaria, Germany, Lithuania, and Poland: A comparison of flat and graduated income tax structures. Atlantic Economic Journal, 46(4), 405-417. https://doi.org/10. 1007/s11293-018-9601-y.

Sussman, S., \& Arnett, J. J. (2014). Emerging adulthood: Developmental period facilitative of the addictions. Evaluation \& the Health Professions, 37(2), 147-155. https://doi.org/10.1177/ 0163278714521812

The Lithuania Tribune (2016). Young people in Lithuania rely on social media for news. https://ithuaniatribune.com/young-people-inlithuania-rely-on-social-media-for-news/.

Trivedi, R. H., \& Teichert, T. (2017). The Janus-faced role of gambling flow in addiction issues. Cyberpsychology, Behavior and Social Networking, 20(3), 180-186. https://doi.org/10.1089/cyber.2016.0453.

Tromholt, M. (2016). The Facebook experiment: Quitting Facebook leads to higher levels of well-being. Cyberpsychology, Behavior and Social Networking, 19(11), 661-666. https://doi.org/10.1089/ cyber.2016.0259.

Ustinavičienė, R., Škèmienė, L., Lukšienè, D., Radišauskas, R., Kalinienè, G., \& Vasilavičius, P. (2016). Problematic computer game use as expression of internet addiction and its association with self-rated health in the Lithuanian adolescent population. Medicina, 52(3), 199-204. https://doi.org/10.1016/j.medici.2016.04.002.

World Health Organization (2018). International classification of diseases for mortality and morbidity statistics (11th Revision). https://icd. who.int/browse11/1-m/en.

World Health Organization (2021). Mental Health. https://www.who.int/ health-topics/mental-health\#tab=tab_1.

Wu, T.-C., Scott, D., \& Yang, C.-C. (2013). Advanced or addicted? Exploring the relationship of recreation specialization to flow experiences and online game addiction. Leisure Sciences, 35(3), 203217. https://doi.org/10.1080/01490400.2013.780497.

Wunsch, K., Kasten, N., \& Fuchs, R. (2017). The effect of physical activity on sleep quality, well-being, and affect in academic stress periods. Nature and Science of Sleep, 9, 117-126. https://doi.org/10. 2147/NSS.S132078.

Zhao, N., \& Zhou, G. (2021). COVID-19 stress and addictive social media use (SMU): Mediating role of active use and social media flow. Frontiers in Psychiatry, 12, 85. https://doi.org/10.3389/fpsyt. 2021.635546.

Publisher's Note Springer Nature remains neutral with regard to jurisdictional claims in published maps and institutional affiliations. 